\title{
A Retrospective Study of Probable Risk Factors for Default on Dots for Tuberculosis at a Tertiary Care Hospital in Western Maharashtra
}

\author{
Dr. Anita Saibannavar ${ }^{1}$, Dr. Sanjay Desai ${ }^{2}$ \\ R.C.S.M. Govt. Medical College, Kolhapur. Maharashtra, India
}

\begin{abstract}
Tuberculosis is an infectious disease globally affecting 9.2 million people and 2 million in India per year. Each smear positive pulmonary tuberculosis patient can infect approximately 10-15 persons per year. The problem of drug defaulter has been commonly observed wherever prolonged therapy has to be given. In tuberculosis, non adherence to prescribed treatment can lead to drug resistance and treatment failure while the patient continues to transmit infection. We carried out a retrospective study in medical college set up in Western Maharashtra. Over a period of three years, 411 patients who were defaulters studied in details to find out probable risk factors for default. Our study concludes that the most influencing risk factors for TB treatment default are productive age group, male predominance, married people, poorly educated status, low socio economic class, long distance residence etc. The problem of default is bound to continue whatever action we might take, defaulters can be reduced to certain extent by correct instructions at the time of diagnosis and each follow up visits. Understanding the specific reasons can help to device steps to reduce the problem.
\end{abstract}

Keywords: Tuberculosis, DOTS, Defaulters, smear positive, risk factors.

\section{Introduction}

Tuberculosis is an infectious disease caused by Mycobacterium tuberculosis and less commonly by other organisms of the 'tuberculosis complex'. The greatest burden of tuberculosis incidence and mortality in developing countries is in adults aged 15-60 years. These include the most productive members of society such as parents, workers and community leaders. Globally, it affects 9.2 million people annually. In India, incidence is 2 million per year.

While there has been a tremendous decrease in tuberculosis cases in developed countries in the last forty years, there has been an increase in the number of tuberculosis cases in developing countries. Every year, each smear positive patient can infect approximately 10-15 persons, thereby increasing the pool of infected persons. Despite decades of intense drive 2 deaths occur every 3 minute due to TB.

Many patients who do not receive Directly Observed Treatment, stop taking drug after 2 months because they feel better. Studies in India and many other countries consistently shows that at least $1 / 3$ rd of the patients do not take medicines regularly, and it is neither possible to predict who these patients will be, nor to reliably prevent noncompliance by improving patient education (8).

In many developing countries, particularly in Asia, acquired drug resistance remains high, because National Tuberculosis Control Programmes in these countries have not been able to achieve a high cure rate over a very long period of time, even after the introduction of short course chemotherapy. Poverty, economic recession and malnutrition make populations more vulnerable to tuberculosis. Recent increase in human migration has rapidly mixed infected with uninfected communities. To make the global situation worse, tuberculosis has formed a lethal combination with
HIV and Diabetes Mellitus. At the same time drug resistant tuberculosis is a growing threat worldwide.

Incomplete and inappropriate treatment of the disease has spawned the development of strain that is resistant to drugs that once destroyed the bacteria in 100 percent of cases. Defaulters are creating more number of drug resistant cases therefore hamper the control of TB \& thus increasing the morbidity and mortality rate.

On the basis of the criterion laid by the WHO, no single country in the world has succeeded in reaching the point of control, i.e. less than $1 \%$ tuberculin positive among children in the age group 0-14 yrs.

Irregularity of drug intake by patients and inadequate duration of chemotherapy are two major operational problems of treatment. Failure of drug collection on due date and loss of patients from treatment are the two serious impediments to the success of domiciliary treatment. Hence behaviour of patients as manifested in the treatment adherence pattern needs to be monitored with greater care under District Tuberculosis Control Programme.

The problem of drug default has been commonly observed wherever prolonged therapy has to be given. In tuberculosis, non-adherence to prescribed treatment could lead to treatment failure and development of drug resistance while the patient continues to transmit infection.

Treatment non-adherence poses many additional problems for the tuberculosis control programme such as, defaulter action, retrieval efforts and change of chemotherapeutic schedules etc., which have an adverse impact due to increase in operational costs. ${ }^{13} \mathrm{An}$ efficient treatment organization is an essential tool in our endeavour to maximize the programme impact. Special emphasis must be lead on ensuring full completion at least during the initial intensive phase which has been shown to lead to $90-95 \%$ sputum 


\section{International Journal of Science and Research (IJSR) \\ ISSN (Online): 2319-7064}

Index Copernicus Value (2013): 6.14 | Impact Factor (2014): 5.611

conversion in most clinical trials of Short Course Chemotherapy.

Repeated patient motivation, regular drug supply, timely patient retrieval and removal of the organizational problems in the way of treatment are the practical steps that need to be taken in any programme. Human nature being what it is, patient who take medicine regularly, voluntarily, without a break are not many. The problem of non- compliance is bound to continue whatever action we might take. However, an understanding of specific reasons can help to device specific steps to reduce the problem. ${ }^{13}$

It is clear that irregularity in drug intake is mainly due to multitude of certain social factors such as poverty, illiteracy, backwardness where deeply entrenched cultures and customs always govern the attitude of the people towards drug intake. To tackle this problem it is suggested firstly to improve the general standards of living, eliminate poverty, illiteracy and backwardness. Secondly, the patients should be fully educated after taking them into confidence and explaining the details of drug intake, gravity of disease etc. Lastly facilities should be provided for patients to continue domiciliary treatment under the supervision of the nearest medical centre after initial check up at district TB clinics to avoid journey and expenses.

\section{Material and Methods}

The retrospective study was carried out at District Tuberculosis Centre, in Western Maharashtra in Govt. Medical college setup. In this study, the definition of defaulter was "A patient who interrupted treatment for 2 months or more" (3). A retrospective study was performed with total 411 patients, who were defaulters during the period of three years were studied retrospectively.

\section{Criteria used for selection of cases were}

1) Patients with sputum smear positive pulmonary tuberculosis because each smear positive patient infects more persons, thereby increasing the pool of infected persons.

2) A patient who is undergoing Short-Course Chemotherapy regimens either CAT I OR CAT II.

3) A patient who interrupted treatment for 2 or more months.

Home visits were made to assess domiciliary stability, family set up, socio-economic background including employment income, details regarding previous treatment and patient's co-operation with regard to treatment. Apart from these, the close relatives of the patients were interviewed to ensure co-operation.

For every patient started on treatment, a full list of addresses was obtained viz.

1) The patient home address

2) The addresses and name of contact person.

3) Place of employment

For Short Course Chemotherapy two regimens were used (Cat I/ Cat II) for sputum positive pulmonary tuberculosis, at DOTs centre. All the cases were interviewed by using pretested proforma.

A total of 411 cases (233 males and 178 females) were included in the study. The preliminary data such as name, age, sex, address, name with address of contact person, religion, marital status, education, occupation, place of employment, total monthly income of family, total family members, type of family, distance between residence of defaulter and treatment centre were recorded.

Patient's initial symptoms before diagnosis, symptoms present when defaulters interviewed, whether they were informed about necessity of completion of drug treatment were recorded. Simultaneously, perceptions about duration of treatment, curability of disease, source of information about tuberculosis, knowledge about causes of tuberculosis were recorded.

Some information was collected from treatment cards e.g. Initial sputum status, whether positive or negative. If positive, which drug regimen is advised, total period of chemotherapy prior to default, defaulter action taken by District Tuberculosis Centre. Each patient was interviewed and reasons for the defaults were collected.

The test of statistical significance used was the Chi-square test applied as a test of "goodness of fit" to determine, if actual number are similar to the expected number- goodness of fit to a theory. $\mathrm{K}$ is the number of classes for ' $\mathrm{X} 2$ in goodness of fit test. Only 'P' values are presented.

\section{Results}

A total of 411 defaulters were studied. The study variables were age, sex, caste, marital status, educational status, occupation, family income i.e. rupees per month, type of family, distance of residence from treatment centre, total period of chemotherapy taken prior to default and reasons of default, initial symptoms present before the diagnosis of pulmonary tuberculosis, symptoms present when defaulters interviewed, whether they were informed about necessity of completion of drug treatment were recorded, defaulter action taken.

Table 1: Age distribution of defaulters

\begin{tabular}{|c|c|c|}
\hline \multirow{2}{*}{$\begin{array}{c}\text { Age group } \\
\text { (years) }\end{array}$} & \multicolumn{2}{|c|}{ Defaulters } \\
\hline & No. & Percentage \\
\hline$<20$ & 93 & 22.63 \\
\hline $21-40$ & 129 & 31.39 \\
\hline $41-60$ & 92 & 22.38 \\
\hline$>60$ & 97 & 23.60 \\
\hline Total & 411 & 100 \\
\hline
\end{tabular}

$X=9.05$, d.f. $=k-l=3: P<0.05$

Maximum numbers of defaulters were in age group 21-40 years, which is the economically productive age group; because these defaulters couldn't get enough time to collect the drugs from treatment centre due to domestic responsibilities. Present study showed statistically significant association between age group and defaulters $(\mathrm{P}<$ $0.05)$. Similar results were obtained in study conducted by G. Singh. He found maximum number of defaulters in the age group of 21-30 years (9). 


\section{International Journal of Science and Research (IJSR) \\ ISSN (Online): 2319-7064 \\ Index Copernicus Value (2013): 6.14 | Impact Factor (2014): 5.611}

In present study, out of 411 defaulters, $56.69 \%$ were males and $43.30 \%$ are females. This study shows statistically significant association between sex and defaulters ( $\mathrm{P}<$ 0.050). R.V. Pande et al(22), V. Sivaraman et al ${ }^{15}$, Suhadev et al ${ }^{13}$ found maximum number of defaulters in males. In the current study, most of the defaulters were males. Most of the families were dependent on males. Due to domestic responsibilities they couldn't get time to collect the drugs.

Table 2: Distribution of defaulters according to religion

\begin{tabular}{|l|l|c|}
\hline \multirow{2}{*}{ Religion } & \multicolumn{2}{|c|}{ Defaulters } \\
\cline { 2 - 3 } & No. & Percentage \\
\hline Hindu & 113 & 27.49 \\
\hline Muslim & 103 & 25.06 \\
\hline Christian & 86 & 20.92 \\
\hline Others * & 109 & 26.52 \\
\hline Total & 411 & 100 \\
\hline
\end{tabular}

$\mathrm{X} 2=4.13$, d.f. $=\mathrm{k}-1=3 ; \mathrm{P}>0.05$

*Others include Parsi, Rajput, and Sikh

In present study, out of 411 defaulters, $27.49 \%$ are Hindu, $25.06 \%$ were Muslim, and $20.92 \%$ were Christians and $26.52 \%$ in others. This study did not show statistically significant association between religion and defaulter.

D. Banerji found no significant association between caste or religion and defaulters. Hans Adriaanse et al (11) showed that there was no significant association between caste or religion and defaulters.

Table 3: Distribution of defaulters as per marital status

\begin{tabular}{|l|l|c|}
\hline \multirow{2}{*}{ Marital Status } & \multicolumn{2}{|c|}{ Defaulters } \\
\cline { 2 - 3 } & No. & Percentage \\
\hline Married & 276 & 67.15 \\
\hline Unmarried & 135 & 32.84 \\
\hline Total & 411 & 100 \\
\hline
\end{tabular}

$X 2=48.26$, d.f. $=\mathrm{k}-1=1 ; \mathrm{P}<0.001$

In present study, married defaulters were $67.15 \%$ and unmarried were $32.84 \%$. There was no defaulter, which was widow or divorced or separated. Due to their responsibilities, maximum defaulters were in married group. Sahadev et al found maximum number of defaulters in married group.${ }^{13}$ In present study, there was highly significant association between marital status and defaulters $(\mathrm{P}<0.001)$.

Table 4: Distribution of defaulters according to educational status

\begin{tabular}{|l|c|c|}
\hline \multirow{2}{*}{ Educational status } & \multicolumn{2}{|c|}{ Defaulters } \\
\cline { 2 - 3 } & No & Percentage \\
\hline Illiterate & 151 & 36.74 \\
\hline Primary school & 120 & 29.20 \\
\hline High school & 89 & 21.65 \\
\hline College & 51 & 12.41 \\
\hline Total & 411 & 100 \\
\hline
\end{tabular}

$\mathrm{X}=53.33$, d.f. $=\mathrm{k}-1=3 ; \mathrm{P}<0.001$

In the present study, $36.74 \%$ of the total defaulters were illiterate. $29.20 \%$ were having educational status up to primary school, $21.65 \%$ up to high school and $12.41 \%$ up to college level. From table 5 it was clear that maximum number of defaulters were ill-literate and numbers were decreasing as the educational status improved. Present study showed highly significant statistical association between educational status and defaulters $(\mathrm{P}<0.001)$. G. Singh et al ${ }^{9}$ showed maximum number of defaulters were ill-literate and decreased in number as educational status improved.

Table 5: Distribution of defaulters according to occupation

\begin{tabular}{|l|l|c|}
\hline \multirow{2}{*}{ Occupation } & \multicolumn{2}{|c|}{ Defaulters } \\
\cline { 2 - 3 } & No & Percentage \\
\hline Students & 78 & 18.98 \\
\hline Unskilled labourers & 89 & 21.65 \\
\hline Skilled labourers & 71 & 17.27 \\
\hline Govt. servants & 54 & 13.14 \\
\hline Housewives & 95 & 23.11 \\
\hline Others & 24 & 5.84 \\
\hline Total & 411 & 100 \\
\hline
\end{tabular}

$X 2=49.43$, d.f. $-\mathrm{k}-1-5 ; \mathrm{P}<0.001$

From Table 5, it was clear that maximum number of defaulters were housewives. This was due to domestic responsibilities. This study showed statistically high significant association between occupation and defaulters ( $P$ $<0.001)$.D. Banerji found no association between defaulters and their occupation (16).

Suhadev et al ${ }^{13}$ observed that maximum number of defaulters was daily wage earners such as painter; construction workers etc. while minimum defaulters were belong to salaried class. Most of the daily wage earners could not get enough time to collect the drugs or undergoing investigations. For these patients, wasting of one day in the treatment centre means loss of daily wages.

Table 6: Distribution of defaulters as per family income (Rupee per month)

\begin{tabular}{|l|l|c|}
\hline \multirow{2}{*}{$\begin{array}{l}\text { Family income } \\
\text { (rupees per month) }\end{array}$} & \multicolumn{2}{|c|}{ Defaulters } \\
\cline { 2 - 3 } & No & Percentage \\
\hline$<1000$ & 168 & 40.88 \\
\hline $1000-5000$ & 133 & 32.36 \\
\hline$>5000$ & 110 & 26.76 \\
\hline Total & 411 & 100 \\
\hline
\end{tabular}

$\mathrm{X}=12.45, \mathrm{~d} . \mathrm{f}=\mathrm{k}-\mathrm{l}=2 ; \mathrm{P}<0.05$

Most of these defaulters were daily wage earners. The current study showed statistically significant association between monthly family income and defaulters $(\mathrm{P}<0.05)$. D. Banerji (16) found no significant association between monthly family income and defaulters.

Table 7: Distribution of defaulters as per type of family

\begin{tabular}{|l|l|c|}
\hline \multirow{2}{*}{ Type of family } & \multicolumn{2}{|c|}{ Defaulters } \\
\cline { 2 - 3 } & No & Percentage \\
\hline Joint & 195 & 47.45 \\
\hline Nuclear & 216 & 52.55 \\
\hline Total & 411 & 100 \\
\hline
\end{tabular}

$X 2=1.073$, d.f. $=k-1=1 ; \mathrm{P}>0.05$

In the present study, out of 411 defaulters $47.45 \%$ patients were from joint family and 53.55\% were from nuclear family. From the above table it is clear that there were more number of defaulters from nuclear family. In the present study there was no significant association between type of family and defaulters $(\mathrm{P}>0.05)$. 


\section{International Journal of Science and Research (IJSR) \\ ISSN (Online): 2319-7064}

Index Copernicus Value (2013): 6.14 | Impact Factor (2014): 5.611

Table 8: Distribution of defaulters as per the distance between the place of residence and treatment centre.

\begin{tabular}{|l|l|c|}
\hline \multirow{2}{*}{ Distance (k. m.) } & \multicolumn{2}{|c|}{ Defaulters } \\
\cline { 2 - 3 } & No & Percentage \\
\hline $0-5$ & 95 & 23.11 \\
\hline $6-10$ & 127 & 30.90 \\
\hline$>10$ & 189 & 45.99 \\
\hline Total & 411 & 100 \\
\hline
\end{tabular}

$\mathrm{X} 2=12.45$, d. f. $=k-1=2 ; \mathrm{P}<0.05$

In the present study, out of 411 defaulters $23.11 \%$ patients were residing at a distance less than or equal to 5 kilometre, $30.90 \%$ patients residing at a distance between 6-10 kilometres from treatment centre. $45.99 \%$ patients were residing at a distance more than 10 kilometres. From the above table it was clear that as the distance between the treatment centre and residence of patient increases, there were more number of defaulters. In the present study there was statistically significant association between number of defaulters and distance between residence and treatment centre $(\mathrm{P}<0.05)$.

Table 9: Distribution of defaulters as per informed the necessity of completion of treatment

\begin{tabular}{|l|l|c|}
\hline \multirow{2}{*}{ Result } & \multicolumn{2}{|c|}{ Defaulters (N =411) } \\
\cline { 2 - 3 } & No & Percentage \\
\hline Informed & 324 & 78.83 \\
\hline Not informed & 65 & 15.81 \\
\hline Don'tknow & 22 & 5.36 \\
\hline
\end{tabular}

Despite most of patients informed regarding necessity of treatment, patient defaulted. This could be due to failure in effective motivation.

Table10: Distribution of defaulters as per the perception about duration of treatment

\begin{tabular}{|l|l|c|}
\hline \multirow{2}{*}{ Treatment duration } & \multicolumn{2}{|c|}{ Defaulters (N =411) } \\
\cline { 2 - 3 } & No & Percentage \\
\hline Don'tknow & 41 & 9.98 \\
\hline 6-8 months & 328 & 79.80 \\
\hline As per Doctor's advise & 18 & 4.38 \\
\hline Till symptoms disappears & 24 & 5.84 \\
\hline
\end{tabular}

From the above table it was clear that 41 (9.97\%) defaulters didn't know the exact duration of treatment. Maximum number of defaulters $(79.80 \%)$ knew the correct duration of treatment (short course chemotherapy).

Table 11: Distribution of defaulters as per period of chemotherapy taken prior to default

\begin{tabular}{|l|l|l|}
\hline \multirow{2}{*}{$\begin{array}{l}\text { Period } \\
\text { (months) }\end{array}$} & \multicolumn{2}{|c|}{ Defaulters (N =411) } \\
\cline { 2 - 3 }$<2$ & No & Percentage \\
\hline $2-3$ & 117 & 28.47 \\
\hline$>3$ & 143 & 34.79 \\
\hline Total & 151 & 36.74 \\
\hline
\end{tabular}

$\mathrm{X} 2=4.61, \mathrm{~d} . \mathrm{f} .=\mathrm{k}-\mathrm{l}=2 ; \mathrm{P}>0.05$

In the current study, there was no statistically significant association between period of chemotherapy taken prior to default and defaulters $(\mathrm{P}>0.05)$.
Table 12: Distribution of defaulters as per the reasons for their Default

\begin{tabular}{|l|l|c|}
\hline \multirow{2}{*}{ Reasons } & \multicolumn{2}{|c|}{ Defaulters (N =411) } \\
\cline { 2 - 3 } & No & Percentage \\
\hline 1.Patient & & \\
Family problem & 98 & 23.84 \\
Occupational problem & 85 & 20.68 \\
Forgetfulness & 70 & 17.03 \\
Long distance & 45 & 10.95 \\
Disagreement with diagnosis & 18 & 4.38 \\
Unsuitable clinical timing & 47 & 11.43 \\
Others & 25 & 6.08 \\
\hline 2.Disease related & & \\
Relief of symptoms & 46 & 9.73 \\
Aggravation of symptoms & 21 & 5.10 \\
\hline 3.Drug related & & \\
Toxicity & 37 & 9.00 \\
No relief of symptoms & 27 & 6.57 \\
\hline & 411 & 100 \\
\hline
\end{tabular}

From the above table it was clear that patient related reasons were more as compared to drug related and disease related reasons.

Similar results were seen in other studies (19).

\section{Discussion}

Tuberculosis is known to man from ancient times and continues to be a major Public Health Problem. The disease affects primarily people in their most productive years of life and is commonly associated with poverty, overcrowding and malnutrition. Lack of education, environmental pollution and poor sanitation compound the problem. The condition of relative deprivation among economically weaker sections of the society and the high tuberculosis case rates in them seems to form a vicious cycle, one aggregating the other.

In the study conducted by NTI, Bengaluru, it was seen that the number of defaulters did not depend upon patient characteristics such as age, sex, occupation, religion, living condition and home distance from treatment place $(10,17)$.

The basic curative as well as preventive strategy is the treatment of newly diagnosed sputum positive pulmonary tuberculosis cases, as they are the main sources of infection and are more likely to die unless effectively treated. Short Course Chemotherapy (SCC) is being gradually introduced since 1986.

Rewards with short course chemotherapy

1) Reduction in the duration of treatment from 12-18 months to 6-9 months.

2) Early sputum conversion

3) No relapse, or even if it is there, it is minimal.

Challenges in the success of short course chemotherapy

1) Drug default

2) Lack of knowledge of proper regimen by the practicing doctor

3) Organizational efforts needed for the success of short course chemotherapy. The belief that because of shorter duration of treatment, defaulter actions, etc. are minimized may not be true. 


\section{International Journal of Science and Research (IJSR) \\ ISSN (Online): 2319-7064}

Index Copernicus Value (2013): 6.14 | Impact Factor (2014): 5.611

A drug defaulter in pulmonary tuberculosis poses a threat not only to himself but also to the community he lives in, by spreading the drug resistant organisms. It poses many additional problems e.g. default actions, retrieval of defaulters and reorganization of the chemotherapeutic schedule. $^{4}$

Patient's compliance with drug therapy for chronic diseases is poor, has been documented in the long-term management of hypertension, diabetes mellitus, in rheumatic fever prophylaxis, as well as in tuberculosis.

Non-compliance represents self-destructive forces in the patient that are poorly understood by both the patient and the health care provider.

Physicians often have a problem with compliance because of their power and status. The patient is upset because he is ill and worried. He perceives the physician as busy and underpressure so that intruding upon his time is an added cause of uneasiness. The doctor is often in hurry, does not take time to listen and forgets or avoids explaining. His prognosis may be discouraging, his therapy protracted and unpleasant.

Tuberculosis has resurfaced as a global emergency in recent years not only in terms of increase in number of cases worldwide but also the emergence of the deadly multidrug resistant tuberculosis. World Health Organization (WHO) has issued a call for the global community to step up its vigilance against the disease. Chemotherapy is the most powerful in the fight against tuberculosis. The patient must be closely monitored for compliance and progress.

Most of the defaulters were present in age group 21-40 years. This is economically productive age group. Most of the defaulters were in this age groups because these defaulters could not get enough time to collect drugs from treatment centre because wasting of that much time obviously affect the daily wages. Similar results were obtained in study conducted by G. Singh (9).

Most of the defaulters were males. It could be due to nonavailability of time due to domestic responsibilities. R.V.Pande (22), V.Sivaraman (15) showed male predominance like our study. In some studies it had been observed that there were no correlation between casts or religion and defaulters. In some it had been found that defaulters are more in backward casts. In our study, no significant association was observed.

Defaulters were more in illiterates because these patients did not insist upon them the importance of domiciliary longterm treatment of tuberculosis. After taking treatment for some period some patients felt well and gave up treatment. These patients did not know the importance of long term treatment. D. Banerji found no significant association with educational status (16).

Most of the defaulters are more in daily wages earners because patients could not get enough time to collect the drugs or undergoing investigations. For these patients, wasting of one day in the treatment centre means loss of daily wages.
Defaulters were having no correlation with family income per month in some studies. It was also found that defaulters were more among the group which having family income less. $(9,13)$

It was found that in some studies there was no co-relation between the types of family whether nuclear or joint (18). But in some studies it was that most of the defaulters were in joint families (9).

It had been observed that in some studies as distance between the centre and the residence of patient increased, there was more number of defaulters. But it was not seen in many studies $(10,16,22)$.

It had been observed from various studies that there were more of defaulters as the period of treatment increases $(14,20,21)$. In other words, there was less number of defaulters in initial months of treatment as compared to subsequent months. During intensive phase the patients were regular, but once they felt better and went into wrong impression of cure/wellbeing, they gave up treatment. At this stage it was more important to insist on them the importance of treatment completion and adverse effects of incomplete and irregular treatment.

\section{Conclusion}

Our study concludes that the most influencing risk factors for treatment default are productive age group, male predominance, married people, poorly educated status, low socio-economic class, distance of treatment centre from patient residence.

Type of family, period of treatment prior to default and religion are not statistically significant contributing risk factors in current study.

Defaulters can be reduced to certain extent by correct instructions at the time of diagnosis and each visit. The importance of regular intake in adequate quantities and for a prescribed duration should be stressed upon the patient. The prevention of default is possible by good motivation initially and during treatment.

\section{Recommendations}

Tuberculosis is a disease which affects a person profoundly at a physical and mental level hence demands greater support at that level. Defaulters can be reduced to certain extent by correct instructions at the time of diagnosis and at the time of each collection. The importance of regular intake in adequate quantities and for a prescribed duration should be stressed upon the patient.

The selection of regimen should be appropriate. Social and economic impediments should be removed as far as possible and above all, there should be machinery to educate and motivate the patients and to take prompt action to retrieve the defaulters. The patients should be fully educated after taking into confidence and explaining the details of drug intake, gravity of disease etc.

\section{Volume 5 Issue 2, February 2016}




\section{International Journal of Science and Research (IJSR) \\ ISSN (Online): 2319-7064}

Index Copernicus Value (2013): 6.14 | Impact Factor (2014): 5.611

Initial motivation should be done first by the medical officer of the centre and then by the health visitor. It should be done in the language best understood by the patient. It should be done at the time of initiation. Directly Observed Therapy will be useful as compared to self- administered treatment. As far as possible, it should be managed by clinical staff rather than para-clinical staff. But this is not possible in case of high case rates.

The problem of defaulters is bound to continue whatever action we might take; however, understanding of the specific reasons can help to devise specific steps to reduce the problem. Besides increasing the visibility of TB programme in the community which may increase knowledge and improve attitude towards TB, an important message needs to be conveyed to the community regarding drug resistance and the treatment availability. Intensive IEC activities are essential. Treatment should be decentralised to the community level, and families of TB patients must be encouraged to fully support TB patients. There is a need for in service training for staff to provide patients with effective counselling. Additional, social support should be extended to the patients. It is necessary to intensify the education campaign on $\mathrm{TB}$, implementing public private mix DOTS.

\section{References}

[1] Vinitha Jaychandean. A case study of tuberculosis treatment defaults in New Delhi. Ann of Tropical med and public Health, 2014 : 7 (124-129)

[2] Sanual, Tomoko et al. Journal of National Institute of Public Health, 2010 Vol.59 No.3j291-297

[3] A. Alam. Tuberculosis Control In Bangladesh. Lancet 1992,339:1181-82.

[4] B.K. Khanna et al. Drug default in Tuberculosis Ind. J. Tub. 1977, Vol. 14, No.3, 121-126

[5] Cummings K.C. et al. Movements of tuberculosis patients and the failure to complete anti- tuberculosis treatment. Am.J. Respir.Crit.Care Med. 1998, Apr: 157:1249-52.

[6] Coulon P. Outcome of patients treated for tuberculosis in Valid Country, Switzerland. Int. J. of Tuberc. Lung Dis. 1998, May: 2(5) 372-377.

[7] David Wilkinson. High compliance tuberculosis treatment programme in a rural community. Lancet 1994, 343: 647-648. v

[8] DGHS, New Delhi, 1999. Managing Revised National Tuberculosis Control Programme in your area. Module $1-4$.

[9] G. Singh et al. A study of defaulters in anti-tuberculosis therapy. Ind. J. Tub. 1976, Vol.23, No.3: 98

[10] Hans Adriaanse. In search of factors responsible for non-compliance among tuberculosis patients in Wardha district, India. Soc. Sci. Med. 1992, 34, 3,291.

[11]Kruyt ML et al. True status of smear positive pulmonary tuberculosis defaulter in Malawi. Int. J. Tub. Lung. Dis 199 July; 3(7): 603-12.

[12]M.A. Seetha. Problem of drug default and role of motivation. Ind. J. Public Health 1982, Vol. 26, and No.4: 234.

[13] Mohanrani Suhadev et al. A retrospective study of noncompliance patients in controlled clinical trials of short course chemotherapy. Ind. J. Tub. 1995, Vol.42,221.
[14]P.C. Jain et al. A study of drug default in patients attending tuberculosis clinic in rural area. Ind. J. Tub. 1981, Vol. 28, No.1: 26

[15] V. Sivaraman et al. Tuberculosis mortality and cure among treatment defaulters: Epidemiological implications. Ind. J. Tub. 1990, Vol. 37: 73

[16] D. Banerji et al. Behaviour of tuberculosis patients towards a treatment organisation offering limited supervision

[17] Banerji D. et al. A sociological inquiry into an urban tuberculosis control programme in India. Bull.WHO 1963, 29, 685.

[18] G.E.Rupert Samuel et al. A current comparison of an unsupervised self administered daily regimen and a fully supervised twice weekly regimen of chemotherapy in a routine outpatient treatment programme.Ind.J.Tub.1974. Vol.11, No. 3,152.

[19] K.S.Aneja et al. Influence of initial motivation on treatment of tuberculosis patients. Ind.J.Tub. 1980, Vol 17 , No. 3,123.

[20]P. Jagota et al. Operational feasibility of an unsupervised intermittent short course chemotherapy regimen at the district TB centre. Ind. J. Tub. 1991, Vol $38: 55$.

[21]R. Paramsivan et al. Short course chemotherapy: A controlled study of indirect defaulter retrieval method. Ind. J. Tub. 1993, Vol. 15, 107.

[22]R. V. Pande et al. Treatment default of tuberculosis patient in a domiciliary service clinic at Lukhnow. Ind. J. Tub. 1968, Vol. 15, 107.

\section{Author Profile}

Dr. Anita Saibannavar, associate professor and head, department of pulmonary medicine, RCSM Govt. Medical College, Kolhapur. Maharashtra (INDIA).

Dr. Sanjay Desai, associate professor and head, department of Radiology, RCSM GMC, Kolhapur. 